\title{
Government Spending Composition, Technical Change and Wage Inequality
}

\author{
Guido Cozzi* Giammario Impullitti ${ }^{\dagger}$
}

This version: December 2008

\begin{abstract}
In this paper we argue that government spending played a significant role in stimulating the wave of innovation that hit the U.S. economy in the late 1970s and in the 1980s, as well as the simultaneous increase in inequality and in education attainment. Since the late 1970's U.S. policy makers began targeting commercial innovations more directly and explicitly. We focus on the shift in the composition of public demand towards high-tech goods which, by increasing the market-size of innovative firms, functions as a de-facto innovation policy tool. We build a quality-ladders nonscale growth model with heterogeneous industries and endogenous supply of skills, and show that increases in the technological content of public spending stimulates $R \& D$, raises the wage of skilled workers and, at the same time, stimulates human capital accumulation. A calibrated version of the model suggests that government policy explains between 12 and 15 percent of the observed increase in wage inequality in the period 1976-91.
\end{abstract}

JEL Classification: E62, H57, J31, 031, 032, 041.

Keywords: R\&D-driven growth theory, heteregeneous industries, fiscal policy composition, innovation policy, wage inequality, educational choice.

\section{Introduction}

In the early 1980s we observe a substantial increase of public investment in high-tech sectors in the U.S.: investment in equipment and software $(\mathrm{E} \& \mathrm{~S})$, which was 20 percent of total government investment in 1980, climbs to about 40 percent in 1990 and to more than 50 percent in $2001 .^{1}$ The composition of private investment also switched towards E\&S but more than a decade later, catching up with the public trend in the 1990s (NSF 2002). Accompanying this acceleration of the technological intensity of public spending we observe an 18 percent increase in the relative wage of skilled workers during the 1980s (CPS 1999).

In this paper we argue that the change in the composition of public spending reallocated marketsize from low-tech to high-tech industries, thus enlarging the market for more innovative products and stimulating innovation. As innovation is a skill-using activity, government policy may have also helped to stimulate the relative demand for skills and raise the skill-premium. Our analysis remarks that although government procurement is not an explicit policy tool, it has often worked as 'de facto' innovation policy instrument.

\footnotetext{
${ }^{*}$ Guido Cozzi, Department of Economics, University of Glasgow. Email: g.cozzi@lbss.gla.ac.uk

${ }^{\dagger}$ Giammario Impullitti, Department of Economics IMT Lucca Institute for Advanced Studies. Email: g.impullitti@imtlucca.it

${ }^{1} \mathrm{E} \& \mathrm{~S}$ includes a group of investment goods that are considered more innovative than those included in structures (see Cummins and Violante 2002 and Hobjin 2001b).
} 
We build a version of the quality-ladder growth model with endogenous supply of skills (Dinopoulos and Segerstrom 1999). A new and key feature of our model is the introduction of heterogeneous industries. The economy is populated by a continuum of monopolistic competitive industries with asymmetric innovation power; in the language of quality-ladders models this implies that each sector has a different quality-jump any time an innovation arrives. In this setting we introduce government policy, in the form of a public spending rule: the government can allocate its expenditure in manufactured goods using a continuum of different policy rules, from the extreme symmetric rule, where each sector gets the same share of public spending, to an asymmetric rule, meaning that the sector with the highest quality jump receives the greatest amount of government spending.

In our model, high-tech sectors are those where innovation brings technological improvements, quality jumps, that are greater than average. There are two activities in the economy: manufacturing, carried out by a continuum of asymmetric firms, and innovation activity or production of ideas. We assume that unskilled labor is used exclusively in manufacturing and that ideas are produced using only skilled labor. As the government reallocates spending from low to high-tech sectors, aggregate profits increase. Intuitively, higher quality jumps in high-tech sectors imply higher mark-ups and larger profits. Hence, a redistribution of public spending in favor of these sectors raises aggregate profits in the economy. In quality-ladder growth models monopoly profits are the rewards for innovation activities, so the increase in total profits produced by the reshuffling of public spending will raise the relative demand for skilled workers.

Finally, there is an education choice in the model that endogenizes skills formation. This implies that, by increasing the skill premium, high-tech public spending will also raise the incentives to train and accumulate skills. Therefore, wage inequality generated by our source of technical change will be a general equilibrium result, where both the supply and the demand for skills are endogenous.

We adopt a broad interpretation of innovation in order to include all of those activities that are targeted to increase firm profits. In our model, workers performing innovative activities are those workers that, with their intellectual skills, contribute to give a firm a competitive advantage over others. Therefore, we do not restrict our view to $R \& D$ activities. While $R \& D$ workers play an important role in innovation, they are not the only skilled workforce that a firm needs to beat its rivals: managerial and organizational activities, marketing, legal and financial services are all widely and increasingly used by modern corporations to compete in the marketplace.

This paper is related to the literature on skill-biased technical change (SBTC). ${ }^{2}$ Like other works in this area, we focus on the role of technical change in affecting the U.S. wage structure in recent decades. In our paper, innovation is skill-biased by assumption, as in models of exogenous SBTC (i.e. Aghion, Howitt, Violante 2002, Caselli 1999, Galor and Moav 2000, Krusell, Ohanian, Rios-Rull, Violante 2000). Strictly speaking, our model is not a model of SBTC in the sense that innovation does not increase the productivity of skilled workers. In our framework, innovation is simply a skillintensive activity, and wage inequality increases with the size of this activity. The innovation activity just described implies that technical change in our model is endogenous, as in models of endogenous

\footnotetext{
${ }^{2}$ For a review of this literature see Acemoglu (2002), Aghion (2002) and Hornstein, Krusell, and Violante (2005).
} 
SBTC, or directed technical change (Acemoglu 1998 and 2002b, Kiley 1998). ${ }^{3}$ We also share with endogenous technology models the following two other features: first, the idea that innovation is profit-driven and that market-size is one key determinant of profitability; second, the exploration of the 'sources' of the type of technical progress at the roots of the observed increase in the skill premium.

The present paper contributes to this literature by exploring a new source of technical change: the technological composition of government spending. The other sources of endogenous bias of technical change analyzed in the literature are the market-size effect produced by trade liberalization (Dinopoulos and Segerstrom, 1999, and Acemoglu, 2003) and the market-size effect produced by an increase in the relative supply of skills (Acemoglu, 1998, and, 2002b). Although our model shares many features with Dinopoulos and Segerstrom (1999) version of the quality-ladder model there are three original departures: first, on the theory side, the presence of heterogeneous industries allows government spending to affect innovation and the skill premium. This is not obtainable by simply introducing government spending into Dinopoulos and Segerstrom's symmetric industries framework. Second, as stated above, while their application focuses on trade liberalization as the source of technical change and wage inequality, we examine the role of government spending. Third, our paper puts a stronger emphasis on quantitative analysis (calibration and simulation). To our knowledge, this is the first attempt to assess qualitatively and quantitatively the relevance of the fiscal policy channel in the debate on technical change and wage inequality in the U.S. These two features represent the main contribution of this paper to the literature. ${ }^{4}$

The paper is organized as follows. Section 2 presents the stylized facts on government policy and wage inequality. Section 3 sets up the model. Sections 4 and 5 derive the main results and explain the intuition for the macroeconomic consequences of asymmetric steady states. In section 6 we calibrate the model to match salient long-run facts of the U.S. economy and focusing on the steady-state perform a quantitative evaluation of our theoretical mechanism. Section 7 shows the transitional dynamics implied by our model. Section 8 concludes.

\section{Stylized facts}

In this section we provide some motivating evidence on the dynamics of public spending composition and wage inequality in recent decades. First, we show how the shift in the composition of government expenditure can be viewed in a context of an overall structural change in innovation policy. Second, we discuss some descriptive evidence on the dynamics of public spending composition and on the increase in the skill premium in the 1970s and 1980s.

Technology policy during the Cold War consisted primarily of funding for basic research, on the one hand, and funding for applied research and development related to federal defense projects on the other. As suggested by Branscomb and Florida (1998), the assumption that these activities would also sustain economic competitiveness was derived from a supply-side picture of the commercial innovation mechanism. On one hand, there was a consensus on the so called 'pipeline model', which conceives

\footnotetext{
${ }^{3}$ Galor and Moav (2000) in section IV introduce endogenous technical change through human capital accumulation.

${ }^{4}$ For a deeper discussion of these three different sources of the endogenous bias of technical change and their implications for wage inequality see Hornstein, Krusell, and Violante (2005).
} 
commercial innovations as spurring automatically from scientific research. The idea was that once the government had provided the basic research, product development and production would follow immediately thanks to the market mechanism. In addition, as a complement to the pipeline model, policy makers assumed that technology created in pursuit of governmental missions, especially defense, space and nuclear energy, would transfer itself to industry automatically and at no cost. This is the 'spin-off hypothesis' that together with the pipeline model formed the basic framework of the U.S. technology policy during the Cold War, also known as the 'Linear model'.

In this vision of the innovation process, policy makers could hit the primary target of the Soviet's security threat (through funds for defense research and mission-oriented development) while having the "positive externality" of stimulating industrial innovation through the pipeline spin-off mechanism. Hence, for policy makers, the linear model had the attractive feature of achieving economic innovation goals without interfering with the autonomy of private firms - government did not have to 'pick winners and losers'.

While this model of science and technology policy was successful in containing Soviet expansionism, in the late 1960's there were early indications, as Japan and Germany recovered from the war and the East Asian NICs became credible competitors on global markets, that defense-based policies were not working equally well in promoting economic security. From the early 1970s to the late 1980s several indicators document the erosion of the US global technological leadership. Between 1980 and 1991 the global market shares of the United States in the high-tech markets declined by 16 percent, while Japan's share increased by about 30 percent (NSF, 1998). Guerrieri and Milana (1991), using a classification scheme for high-tech sectors different form the OECD scheme, found that Japan's share of high-tech export doubled from about 7 percent in 1970-73 to about 16 percent in 1988-89, while the US share declined from 30 percent to about 21 percent. Interestingly, the data on global leadership in R\&D investment mirror the evidence on global market shares. More precisely, using OECD ANBERD data on R\&D investment for two and three-digit manufacturing industries, Impullitti (2008a) shows that the U.S. share of global R\&D investment declined from 52 percent in 1973 to 37 percent in 1991, while Japan's share increased from 17 percent in 1973 to 28 percent in 1991. Finally, the loss of U.S. leadership in both markets and R\&D shares is concentrated in the major high-tech sectors. ${ }^{5}$

Concerns over U.S. global competitiveness in the late 1970s and early 1980s led to a series of legislative changes that collectively created an institutional environment more favorable to commercial innovation. The introduction of this set of policies, explicitly targeted at improving the commercialization of technological advances and thus clearly at odds with the linear model, can be considered as a structural change in the U.S. system of innovation (Mowery and Rosenberg 1989 and 1993, Ham and Mowery 1995, Krimsky 2003, and Mirowsky and Sent 2005). The new strategy involved both innovation cost-reducing measures and demand-pull policies.

\footnotetext{
${ }^{5}$ The erosion of the American position in global high-tech markets was especially pronounced in electronics, a sector in which Japan and East Asian new industrialized countries scored dramatic gains; and in aircrafts and parts, where the competitiveness of European products increased rapidly (Guerrieri Milana 1991, and Tyson 1992). The larger drop in the U.S. R\&D shares takes place in Office and Computing Machineries (OCM), which accounts on average for 8 percent of total manufacturing R\&D and in Radio, TV, and Communication Equipment (RTCE), which accounts on average for 16 percent of total R\&D: the U.S. share dropped from 0.76 to 0.53 in OCM and from 0.54 to 0.4 in RTCE, while Japan's share rose from 0.06 to 0.32 in OCM and from 0.13 to 0.26 in RTCE (Impullitti 2008a).
} 
The set of innovation cost-reducing policies introduced in this period basically work through the following channels: subsidies for R\&D, technology transfer, and property rights protection. The Research \& Experimentation Tax Credit established by the Economic Recovery Tax Act of 1981 was aimed at introducing tax subsidies to annual increases in R\&D investment. Technology transfer policies are represented by the Stevenson-Wydler Technology Innovation Act (1980), that required Federal Laboratories to facilitate the transfer of federally owned and originated technology to the private sector and to local and state governments. The Small Business Innovation and Development Act (1982), that established the Small Business Research (SBIR) program within the major Federal $\mathrm{R} \& \mathrm{D}$ agencies to increase government funding of research with commercialization potential within small, high-technology companies. The Federal Technology Transfer Act (1986), that amended the Stevenson-Wydler Act, to authorize cooperative research and development agreements (CRADA) between Federal laboratories and other entities, including state agencies. Finally, policies to improve protection of intellectual property rights are the Bayh-Dole Patent Act (1980), which allowed agencies to issue patents to small business and non profit institutions, including universities, for inventions made with agency funds; and the Court of Appeals for the Federal Circuit, established in 1982, that substantially improved the protection of intellectual property right in litigations.

The contemporaneous introduction of this set policies was strongly aimed at creating an institutional environment that could promote commercial innovation. This constitutes a change in the structure of U.S. innovation policy, away from the massive spending in military technology of the post-War period. Mowery (1998) argues that this set of policies represent a "structural change" in the US. national innovation system. There is sufficient consensus among technology policy scholars that the post-1980 shift, started during the Reagan and Bush administrations and continued as a trademark of Clinton's economic policy, represents a crucial move towards an explicit commercial innovation policy in the US. ${ }^{6}$

On the demand side, shifts in the composition of government spending towards innovation-intensive goods can also be seen as part of this structural change in U.S. innovation policy. Although government spending has never been an explicit policy tool, it has always worked as a de facto relevant innovation policy instrument. David Hart presents the argument in the following way: "[Public] R\&D spending was typically accompanied by other measures that deserve at least as much credit for their technological payoffs. For instance, the Department of Defense (DOD) not only funded much of the physical science and engineering R\&D that led to advances in semiconductors and computers, it also purchased a large fraction of products themselves, especially the most advanced products. The DOD guaranteed that a market for electronics would exist, inducing private investment on a scale that would not have otherwise followed even the most promising research results" (Hart 1998 p.1). Hence, according to this view, public procurement guaranteed a market to innovative firms, especially in early stages of product development. There is evidence that the DOD, NASA and also other government agencies, such as the Department of Health, contributed to private innovation via demand-pull (see Ruttan 2003, and Finkelstein 2003).

\footnotetext{
${ }^{6}$ See Mowery and Rosenberg (1989) and (1993), Ham and Mowery (1995), Krimsky (2003), and Mirowsky and Sent (2005). For further discussion of the nature and empirical relevance of the shift in technology policy see Impullitti (2008b).
} 
In this paper we propose an aggregate measure of this demand-pull channel for innovation. We use BEA NIPA data that break down public investment between Equipment and Software (E\&S henceforth) and Structures. E\&S includes a group of investment goods that are considered more innovative than those included in structures, so we choose E\&S as our high-tech aggregate. ${ }^{7}$ The focus on investment is due to the fact that there is no aggregate data keeping track of the technological composition of public consumption expenditures.

In figure 1 we report the evolution of the skill premium and of the composition of government investment spending, expressed as the ratio of government investment in E\&S over total government investment. We can see that the share of public investment devoted to the high-tech aggregate, E\&S, is fairly constant from the early 1960s to the late 1970s, fluctuating between 16 and 20 percent. It then increases steadily in the 1980s, reaching 41 in 1991, and it keeps growing, but to a slower pace, in the 1990s till reaching 48 percent in 1999. In the figure we also see the well known dynamics of the skill premium that after declining for most of the 1970s experiences a strong acceleration in the late 1970s. ${ }^{8}$ The relevant fact here is that both series jump from a fairly steady course to a rapidly increasing one during the late 1970s, early 1980s. This common and contemporaneous change trends suggests that the shift towards high-tech public spending, which began around 1974 and radically accelerated around 1978, might have had an influence on rising inequality in the 1980s. ${ }^{9}$

\section{[FIGURE 1 ABOUT HERE]}

Using the same data we find that also the composition of private investment progressively shifted towards E\&S since the late 1970s. However, the technological composition of public investment accelerated in the 1980s -the period when wage inequality increased more rapidly- while the rise of private investment in E\&S was concentrated in the 1990s. More precisely, the yearly average growth rate of private investment was 9 percent while the growth rate of public investment was 16 percent in the period 1970-90; while private spending jumped on those high growth rates only in the 1990s. ${ }^{10}$

As $R \& D$ represents an important part of innovation activity, figure 2 shows that, as was the case for the composition of public spending, the trend of private R\&D/GDP also increases substantially in the late 1970s, along with that of the skill premium. The technological composition of government

\footnotetext{
${ }^{7}$ The recent empirical literature on sector-specific technical change confirms the idea that high-tech sectors have been the major engine of innovation in the last decades (See Hornstein et al., 2005)). Cummins and Violante (2002) find the average technical change in E\&S over the last 30 years in the U.S. to be between 5 and 6 percent. In this literature, the change in E\&S is proxied by the difference in growth rates between constant-quality consumption prices and qualityadjusted prices of investment in E\&S. The substantial decline of the quality-adjusted price of capital equipment since the early 1970s provides evidence of E\&S-specific technical change. Recently some empirical works have shown that, although technical change in structures is less relevant than in equipment goods, it has been positive and significative in the last decades. Gort, Greenwood and Rupert (1999) find a 1 percent yearly average structures-specific technical change during the last three decades.

${ }^{8}$ The skill premium series has been obtained merging Krusell, Ohanian, Rios-Rull and Violante (2000) data and Current Population Survey (1999) data, considering 1963 as the base year.

${ }^{9}$ We are not interested in explaining the decline in the skill premium observed in the 1970s. For this reason the weaker correlation between the two series in the 1970s does not affect our argument. In the literature, the decline of the skill premium in the 1970s has been mainly attributed to an exogenous increase in the relative supply of college graduates in those years, produced by the arrival on the job market of the Baby Boomers generation, and to the increase in college enrollment produced by the Vietnam War draft. See Acemoglu (2002a) for a discussion.

${ }^{10} \mathrm{We}$ also find that the ratio of public to private investment in the innovative aggregate has been betwen 13 and 26 percent in the period 1970-90. This indicates that the scale of public E\&S is not negligible in the period of interest.
} 
spending affects the market-size of all kinds of innovation activities, of which R\&D is a relevant component.

\section{[FIGURE 2 ABOUT HERE]}

In our opinion this set of facts provides a sufficient motivation to dig deeper into the links between public spending composition, innovation and wage inequality.

\section{The model}

\subsection{Households}

Households differ in their members' ability to become skilled workers, and the ability $\theta$ is uniformly distributed over the unit interval. Households have identical intertemporally additive, separable, and unit elastic preferences for an infinite set of consumption goods indexed by $\omega \in[0,1]$, and each is endowed with a unit of labor/study time whose supply generates no disutility. Households choose their optimal consumption bundle for each date by solving the following optimization problem:

$$
\max \int_{0}^{\infty} N_{0} e^{-(\rho-n) t} \log u_{\theta}(t) d t
$$

subject to

$$
\begin{gathered}
\log u_{\theta}(t) \equiv \int_{0}^{1} \log \left[\sum_{j=0}^{j^{\max }(\omega, t)} \lambda^{j}(\omega) q_{\theta}(j, \omega, t)\right] d \omega \\
c_{\theta}(t) \equiv \int_{0}^{1}\left[\sum_{j=0}^{j^{\max (\omega, t)}} p(j, \omega, t) q_{\theta}(j, \omega, t)\right] d \omega \\
W_{\theta}(0)+Z_{\theta}(0)-\int_{0}^{\infty} N_{0} e^{-\int_{0}^{t}(r(\tau)-n) d \tau} T(t) d t=\int_{0}^{\infty} N_{0} e^{-\int_{0}^{t}(r(\tau)-n) d \tau} c_{\theta}(s) d t
\end{gathered}
$$

where $N_{0}$ is the initial population and $n$ is its constant growth rate, $\rho$ is the common rate of time preference, with $\rho>n$ and where $r(t)$ is the market interest rate. $q_{\theta}(j, \omega, t)$ is the per-member flow of good $\omega \in[0,1]$ of quality $j \in\{0,1,2, \ldots\}$ purchased by a household of ability $\theta \in(0,1)$ at time $t \geq 0$. $p(j, \omega, t)$ is the price of good $\omega$ of quality $j$ at time $t, c_{\theta}(t)$ is nominal expenditure, and $W_{\theta}(0)$ and $Z_{\theta}(0)$ are human and non-human wealth levels. A new vintage of a good $\omega$ yields a quality equal to $\lambda(\omega)$ times the quality of the previous vintage, with $\lambda(\omega)>1$. Different versions of the same good $\omega$ are regarded by consumers as perfect substitutes after adjusting for their quality ratios, and $j^{\max }(\omega, t)$ denotes the maximum quality in which good $\omega$ is available at time $t$. As is common in quality ladders models, we assume price competition ${ }^{11}$ at all dates, which implies that in equilibrium only the top quality product is produced and consumed in positive amounts. $T(t)$ is a per-capita lump-sum tax.

The instantaneous utility function has unitary elasticity of substitution, implying that goods are perfect substitutes, once you account for quality. Thus, households maximize static utility by spreading their expenditures evenly across the product line and by purchasing in each line only the product with

\footnotetext{
${ }^{11}$ All qualitative results maintain their validity under the opposite assumption of quantity competition.
} 
the lowest price per unit of quality, that is the product of quality $j=j^{\max }(\omega, t)$. Hence, the household's demand of each product is:

$$
q_{\theta}(j, \omega, t)=\frac{c_{\theta}(t)}{p(j, \omega, t)} \quad \text { for } j=j^{\max }(\omega, t) \text { and is zero otherwise }
$$

The presence of a lump sum tax does not change the standard Euler equation:

$$
\frac{\dot{c}_{\theta}(t)}{c_{\theta}(t)}=r(t)-\rho
$$

Individuals are finitely-lived members of infinitely-lived households, being continuously born at rate $\beta$ and dying at rate $\delta$, with $\beta-\delta=n>0 ; D>0$ denotes the exogenous duration of their life ${ }^{12}$. People are altruistic in that they care about their household's total discounted utility according to the intertemporally additive functional shown in (1). They choose to acquire education and become skilled, if at all, at the beginning of their lives, and the (positive) duration of their schooling period, during which the individual cannot work, is set at $T_{r}<D$.

Hence an individual with ability $\theta$ decides to acquire education if and only if:

$$
\int_{t}^{t+D} e^{-\int_{t}^{s} r(\tau)} w_{L}(s) d s<\int_{t+T_{r}}^{t+D} e^{-\int_{t}^{s} r(\tau)} \max (\theta-\gamma, 0) w_{H}(s) d s,
$$

with $0<\gamma<1 / 2$. The ability parameter is defined so that a person with ability $\theta>\gamma$ is able to accumulate skills (human capital) $\theta-\gamma$ after schooling, while a person with ability below this cut-off gains no human capital from schooling.

We will focus on the steady-state analysis, in which all variables grow at constant rates and where $w_{L}, w_{H}$, and $c_{\theta}$ are all constant. It follows that $r(t)=\rho$ at all dates, and that the individual will train if and only if her ability is higher than

$$
\theta_{0}=\left[\left(1-e^{-\rho D}\right) /\left(e^{-\rho T_{r}}-e^{-\rho D}\right)\right] \frac{w_{L}}{w_{H}}+\gamma \equiv \sigma \frac{w_{L}}{w_{H}}+\gamma .
$$

The supply of unskilled labor at time $t$ is:

$$
L(t) \equiv \theta_{0} N(t)=\left(\sigma \frac{w_{L}}{w_{H}}+\gamma\right) N(t) .
$$

We set $w_{L}=1$, so that the unskilled wage becomes our numeraire. A fraction $\left(1-\theta_{0}\right)$ of the population decides to receive education. The skilled workforce is represented by those people that have completed their schooling period, that is individuals born between $t-D$ and $t-T r$ :

$$
\int_{t-D}^{t+T r} \beta\left(1-\theta_{0}\right) N(s) d s=\left(1-\theta_{0}\right) \phi N(t) .
$$

with $0<\phi=\left(e^{n\left(D-T_{r}\right)}-1\right) /\left(e^{n D}-1\right)<1$. The uniform distribution of workers abilities implies that the average skills of workers that have acquired education is $\left[\left(\theta_{0}-\gamma\right)+(1-\gamma)\right] / 2$. Hence, the supply of skilled labor in efficiency units at time $s$ is

$$
H(t)=\left(\theta_{0}+1-2 \gamma\right)\left(1-\theta_{0}\right) \phi N(t) / 2,
$$

\footnotetext{
${ }^{12}$ As in Dinopoulos and Segerstrom (1999), it is easy to show that the above parameters cannot be chosen independently, but that they must satisfy $\delta=\frac{n}{e^{n D}-1}$ and $\beta=\frac{n e^{n D}}{e^{n D}-1}$ in order for the number of births at time $t$ to match the number of deaths at $t+D$.
} 
In steady state the growth rate of $L(t)$ and $H(t)$ is equal to $n$.

\subsection{Manufacturing}

Firms can hire unskilled workers to produce any consumption good $\omega \in[0,1]$ of the second best quality under a constant returns to scale (CRS) technology with one worker producing one unit of product. However, in each industry the top-quality product can be manufactured only by the firm that has discovered it, whose rights are protected by a perfectly enforceable patent law.

As usual in Schumpeterian models with vertical innovation (see e.g. Grossman and Helpman, 1991, and Aghion and Howitt, 1992) the next best-quality of a given good is invented by means of innovation activity performed by challenger firms in order to earn monopoly profits that will be destroyed by the next innovator. During each temporary monopoly the patentholder can sell the product at prices higher than the unit cost. We assume that the patent expires when further innovation occurs in the industry. Hence monopolist rents are destroyed not only by obsolescence but also because a competitive fringe can copy the product using the same CRS technology.

The unit elastic demand structure ${ }^{13}$ encourages the monopolist to set the highest possible price to maximize profits, but the existence of a competitive fringe sets a ceiling to it equal to the lowest unit cost of the previous quality product. This allows us to conclude that the price $p\left(j^{\max }(\omega, t), \omega, t\right)$ of every top quality good is:

$$
p\left(j^{\max }(\omega, t), \omega, t\right)=\lambda(\omega), \text { for all } \omega \in[0,1] \text { and } t \geq 0 .
$$

Our fiscal policy tool will be sector specific per-capita public spending $G(\omega, t) \geq 0$, for all $\omega \in[0,1]$ and $t \geq 0$. The government uses tax revenues to finance public spending in different sectors and we assume that the government budget is balanced at every date: $N(t) T(t)=N(t) \int_{0}^{1} G(\omega, t) d \omega$. Moreover, we will assume $N(t) T(t)<\gamma N(t)$, in order to guarantee that public expenditure is feasible. Since we are interested in steady states, in which per-capita variables are constant, from now on we will drop time indexes from per-capita taxation and per-capita expenditures.

From the static consumer demand (2) we can immediately conclude that the demand for each product $\omega$ is:

$$
\frac{N(t) \int_{0}^{1} c_{\theta} d \theta}{\lambda(\omega)}+\frac{N(t) G(\omega)}{\lambda(\omega)} \equiv \frac{c N(t)}{\lambda(\omega)}+\frac{N(t) G(\omega)}{\lambda(\omega)}=q(\omega)
$$

where $c=\int_{0}^{1} c_{\theta} d \theta$ is average per-capita consumption. Sectorial market-clearing conditions imply that demand equals production of every consumption good by the firm that monopolizes it, $q(\omega)$. It follows that the stream of profits accruing to the monopolist which produces a state-of-the-art quality product will be equal to:

$$
\pi(\omega)=q(\omega)(\lambda(\omega)-1)=(c N(t)+G(\omega) N(t))\left(1-\frac{1}{\lambda(\omega)}\right) .
$$

A firm that produces good $\omega$ has an expected discounted value of

$$
v(\omega)=\frac{\pi(\omega)}{r+I(\omega)-\frac{\dot{v}(\omega, t)}{v(\omega, t)}}=\frac{q(\omega)(\lambda(\omega)-1)}{r+I(\omega)-\frac{i(\omega, t)}{v(\omega, t)}},
$$

\footnotetext{
${ }^{13}$ Any CES utility index with elasticity of substitution not greater than one would imply this result.
} 
where $I(\omega)$ denotes the Poisson arrival rate of an innovation that will destroy the monopolist's profits in industry $\omega$. This can be obtained assuming efficient financial markets which in equilibrium equalize the expected return of investing in $\mathrm{R} \& \mathrm{D}$ to the risk-free interest rate $r$. In a steady state where percapita variables all grow at the same rate, it is easy to prove that $\frac{\dot{v}(\omega, t)}{v(\omega, t)}=n$, and from the Euler equation (3) we obtain $r=\rho$. Hence the expected value of a firm becomes

$$
v(\omega)=\frac{q(\omega)(\lambda(\omega)-1)}{\rho+I(\omega)-n} .
$$

\subsection{Innovation races}

In each industry leaders are challenged by the innovation activity of followers that employ skilled workers and produce a probability intensity of inventing the next version of their products. The arrival rate of innovation in industry $\omega$ at time $t$ is $I(\omega, t)$, and it is the aggregate summation of the Poisson arrival rate of innovation produced by all $R \& D$ firms targeting product $\omega$.

In each sector new ideas are introduced according to a Poisson arrival rate of innovation by use of a CRS technology characterized by the unit cost function $b w_{H} X(\omega, t)$, with $b>0$ common in all industries, and $X(\omega, t)>0$ measuring the difficulty of innovation in industry $\omega$. Hence the production of ideas is formally equivalent to buying a lottery ticket that confers to its owner the exclusive right to the corresponding innovation profits, with the aggregate rate of innovation proportional to the "number of tickets" purchased. The Poisson specification of the innovative process implies that the individual contribution to innovation by each skilled labor unit gives an independent (additive) contribution to the aggregate instantaneous probability of innovation: hence innovation productivity is the same if each skilled worker undertakes her activity by working alone as when she works with others in large firms.

The technological complexity index $X(\omega, t)$ has been introduced into endogenous growth theory after Charles Jones' (1995) empirical criticism of R\&D based growth models that generate scale effects in the steady state per-capita growth rate. According to Segerstrom's (1998) interpretation of Jones' (1995) solution to the "strong scale effect" problem (Jones 2005), $X(\omega, t)$ is increasing in the accumulated stock of effective innovation:

$$
\frac{\dot{X}(\omega, t)}{X(\omega, t)}=\mu I(\omega, t)
$$

with positive $\mu$, thus formalizing the idea that early discoveries fish-out the easier inventions first, leaving the most difficult ones for the future. This formulation implies that increasing difficulty of innovation causes per-capita GDP growth to vanish over time unless an ever-increasing share of resources are invested in innovation, thereby requiring a growing educated population. As it will become clearer later, this specification of the difficulty index leads to a version of the quality ladder model where the steady-state growth rate is proportional to the population growth rate, and policy shocks have only temporary effects on growth ${ }^{14}$. For this reason these frameworks are also called

\footnotetext{
${ }^{14}$ Cozzi (2005 and 2007) has proved that in quality ladder economies the steady state growth rate could be affected by self-fulfilling prophecies, despite the "semi-endogenous" structure. Hence sunspots may matter also in this model.
} 
"semi-endogenous" growth models. ${ }^{15}$

For industries targeted by innovation, the following free entry condition applies:

$$
v(\omega) \equiv \frac{q(\omega)(\lambda(\omega)-1)}{\rho+I(\omega)-n}=b w_{H} X(\omega) .
$$

where the marginal benefit of innovation is equated to the marginal cost. The usual Arrow or "replacement effect" implies that the monopolist does not find it profitable to undertake any innovation activity at the equilibrium wage (Aghion and Howitt 1992).

\section{Balanced growth paths}

We are now in a position to analyze the general equilibrium implications of the previous setting. Since each final good monopolist employs unskilled labor to manufacture each commodity, the unskilled labor market equilibrium is

$$
N(t) \theta_{0}=\int_{0}^{1} q(\omega) d \omega=\int_{0}^{1} N(t)\left(\frac{c}{\lambda(\omega)}+\frac{G(\omega)}{\lambda(\omega)}\right) d \omega=N(t)[\Gamma c+\Omega] .
$$

Therefore:

$$
c=\frac{\theta_{0}-\Omega}{\Gamma},
$$

where $\Gamma=\int_{0}^{1} \frac{1}{\lambda(\omega)} d \omega$ and $\Omega=\int_{0}^{1} \frac{G(\omega)}{\lambda(\omega)} d \omega$. Eq.s (8), (10), and (12) imply that

$$
\frac{N(t)}{\lambda(\omega)}[c+G(\omega)]=b w_{H} X(\omega) \frac{\rho+I(\omega)-n}{(\lambda(\omega)-1)},
$$

which - since $w_{H}=\frac{\sigma}{\theta_{0}-\gamma}$ and (14) holds - can be rewritten as:

$$
\frac{1}{\lambda(\omega)}\left(\frac{\theta_{0}-\Omega}{\Gamma}+G(\omega)\right)=\frac{b \sigma}{\theta_{0}-\gamma} x(\omega) \frac{\rho+I(\omega)-n}{\lambda(\omega)-1}, \text { for all } \omega \in[0,1]
$$

where $x(\omega, t) \equiv \frac{X(\omega, t)}{N(t)}$ denotes the population-adjusted degrees of complexity of product $\omega$, which will be constant in steady-state. Similarly, the skilled labor market equilibrium implies:

$$
\left(\theta_{0}+1-2 \gamma\right)\left(1-\theta_{0}\right) \phi / 2=b \int_{0}^{1} I_{\omega} x(\omega) d \omega
$$

In steady state all per-capita variables are constant and therefore $\frac{\dot{X}(\omega, t)}{X(\omega, t)}=n$. Hence, the specification of the R\&D difficulty index (TEG) implies $I=n / \mu$. Hence we can rewrite (16) and (17) as follows:

$$
\begin{gathered}
\frac{1}{\lambda(\omega)}\left(\frac{\theta_{0}-\Omega}{\Gamma}+G_{\omega}\right)=\frac{b \sigma}{\theta_{0}-\gamma} x(\omega) \frac{\rho+n / \mu-n}{\lambda(\omega)-1}, \text { for all } \omega \in[0,1], \\
\left(\theta_{0}+1-2 \gamma\right)\left(1-\theta_{0}\right) \phi / 2=b \frac{n}{\mu} \int_{0}^{1} x(\omega) d \omega \equiv b \frac{n}{\mu} \bar{x}
\end{gathered}
$$

\footnotetext{
${ }^{15}$ See Aghion and Howitt (2005) and Jones (2005) for a discussion of semi-endogenous and fully-endogeous growth models.
} 
In the present framework with quality-improving goods, growth is interpreted as the increase over time of the representative consumer utility level, hence the symmetric growth rate is obtainable from (1) as follows:

$$
\ln u(c(t))=\int_{0}^{1} \ln \left(\frac{c}{\lambda(\omega)}\right) d \omega+\ln \int_{0}^{1} \lambda(\omega) d \omega=\ln \left(\frac{c}{\lambda(\omega)}\right)+\int_{0}^{1} \Lambda(\omega, t) \ln \lambda(\omega) d \omega
$$

where $\Lambda(\omega, t)=\int_{0}^{t} I(\omega, \tau) d \tau$ is the expected number of innovations in industry $\omega$ before time $t$. Since in steady-state $I(\omega, \tau)=I=n / \mu$, we obtain $\Lambda(\omega, t)=\int_{0}^{1}\left[\int_{0}^{t} I(\omega, \tau) d \tau\right] d \omega=t I=t(n / \mu)$. The growth rate is obtained by differentiating $\ln u(c(t))$ with respect to $t$ :

$$
g=\frac{\dot{u}}{u}=I \int_{0}^{1} \log \lambda(\omega) d \omega=n / \mu \int_{0}^{1} \log \lambda(\omega) d \omega .
$$

As usual in semi-endogenous growth models with increasing complexity the steady-state arrival rate of innovation in every industry is a linear increasing function of the population growth rate, and the stationary growth rate is pinned down by population growth. Growth is semi-endogenous in the sense that policy has only temporary effects on the growth rate. Every policy measure capable of increasing the innovation arrival rate $I(\omega)$, and thus the growth rate, will also raise the R\&D difficulty index $X(\omega)$ according to (TEG) and in the long-run the growth rate will not be affected. For what follows it is important to notice that, although policy has no effects on steady-state growth, it has permanent level effects. In particular, since we are interested in the relative demand and supply of skills, we will see that temporary changes in the innovation arrival rate will affect these levels (or ratios) permanently.

Proposition 1 If $\frac{\Omega-\Gamma \bar{G}}{\Gamma}<\frac{(1-2 \gamma) \phi \mu \sigma(\rho+n / \mu-n)}{2 n \gamma}$ a steady state always exists for every distribution of $\lambda(\omega)>1$ and $G(\omega)>0$. At each steady state the following properties hold:

a. $G(\omega)>G\left(\omega^{\prime}\right)$ implies $x(\omega)>x\left(\omega^{\prime}\right)$ and $\partial x(\omega) / \partial G(\omega)>\partial x\left(\omega^{\prime}\right) / \partial G\left(\omega^{\prime}\right)$ iff $\lambda(\omega)>\lambda\left(\omega^{\prime}\right)$

b. $\theta_{0}$ is an increasing function of $\Omega$

Proof. See the Appendix.

Proposition 1a suggests that an increase in government spending in sector $\omega$ stimulates innovation in that specific industry through a market size effect - according to (TEG) the difficulty index $x(\omega)$ is proportional to investment in innovation in sector $\omega$. Moreover the proposition shows that 1 dollar of government spending is more effective in stimulating innovation when directed towards sectors with high quality jumps. The importance of proposition $1 \mathrm{~b}$ will become clearer later; for the moment it suffices to note that it shows that the share of unskilled workers $\theta_{0}$ is increasing with the technologyadjusted average government spending $\Omega{ }^{16}$

\section{$5 \quad$ Fiscal policy rules}

Here we specify rules for public spending and derive the basic result of the paper. The fiscal policy rule that we use is a linear combination of two extreme rules: a perfectly symmetric rule in which every sector gets the same share of public spending, that is $G(\omega)=\bar{G}$, and a rule that allocates public

\footnotetext{
${ }^{16}$ The average goverment spending is $\bar{G}=\int_{0}^{1} G_{\omega} d \omega$.
} 
spending in proportion to the quality jump in innovation, that is $G(\omega)=\bar{G} \frac{\lambda(\omega)}{\bar{\lambda}}$. A linear combination of the two extreme rules yields the general rule

$$
G(\omega)=(1-\alpha) \bar{G}+\alpha \bar{G}(\lambda(\omega) / \bar{\lambda}),
$$

with $0 \leq \alpha \leq 1$.

Proposition 2 Every move from a symmetric spending rule to a rule promoting more heavily sectors with above-average quality-jumps, that is an increase in $\alpha$, increases both the relative demand and the relative supply of skills. The relative demand shift is relatively stronger and the skill premium $w_{H}$ rises.

Proof. The general rule yields $\Omega=\bar{G}\left[\int_{0}^{1} \frac{1-\alpha}{\lambda(\omega)} d \omega+\frac{\alpha}{\bar{\lambda}}\right]$ and deriving $\Omega$ with respect to $\alpha$ we obtain $\partial \Omega / \partial \alpha=\bar{G}\left[-\int_{0}^{1} \frac{1}{\lambda(\omega)} d \omega+\frac{1}{\lambda}\right]:$ Jensen's inequality implies that $\partial \Omega / \partial \alpha<0$. Thus, a shift to more asymmetric spending (an increase in $\alpha$ ) decreases $\Omega$ that, according to Proposition 1.a, generates a decrease in the share of the population that decides not to acquire skills, $\theta_{0}$. Recalling that the skill premium is $w_{H}=\sigma /\left(\theta_{0}-\gamma\right)$, we conclude that a higher $\alpha$ leads to higher wage inequality.

Proposition 2 contains the basic result of the model: when government switches to a policy promoting high-tech sectors more aggressively there is an increase in both the relative supply and demand of skilled workers, but the latter dominates and the skill premium rises. This theoretical result matches two well known stylized facts of the US labor market in the 1980s: the contemporaneous increase in the skill premium and in the relative supply of skilled workers (see Acemoglu 2002a figure 1). This result is directly related to our heterogeneous-industry setting. One dollar of public money in more innovative sectors yields more additional profits than those lost taking one dollar away from less innovative sectors, and the net result is an increase in aggregate profits and innovation activity. ${ }^{17}$ When industries are symmetric the profit rate is the same in all industries and aggregate profits are not affected by a reshuffling of government spending. As stated in proposition 1.a., public spending is, at the margin, more efficient when directed to more innovative industries, that is: $G(\omega)>G\left(\omega^{\prime}\right)$ implies $x(\omega)>x\left(\omega^{\prime}\right)$ and $\partial x(\omega) / \partial G_{\omega}>\partial x\left(\omega^{\prime}\right) / \partial G\left(\omega^{\prime}\right)$ if and only if $\lambda(\omega)>\lambda\left(\omega^{\prime}\right) .{ }^{18}$ Thus, reshuffling public spending towards sectors with higher innovation potential raises the overall innovation activity until the increase of the difficulty index brings back the economy to the exogenous growth rate $g$. Since innovation has become more difficult, to keep the steady-state growth rate we need more labor resources invested in innovation, thus the increase in the 'level' of labor demand produced by the policy shock is permanent.

Finally, the increase in the relative demand for skills raises the skill premium and triggers, through the skill-acquisition process, an increase in the relative supply of skills. Proposition 2 shows that the demand shift dominates the supply and that in equilibrium the skill premium rises.

\footnotetext{
${ }^{17}$ From (9) we know that $\lambda(\omega)$ coincides with the markup over the unit cost for the sector $\omega$. It follows that markups are higher in high-tech sectors.

${ }^{18}$ Notice that increases in the arrival rate of innovation show up in a higher steady-state difficulty index $x(\omega)$, and does not affect the steady-state innovation and the growth rate $g$.
} 


\section{Quantitative analysis}

The data shown in figure 1 suggest a correlation between the composition of public spending and the skill premium. The model presented above provides one possible economic mechanism to explain that correlation. In this section we try to measure the quantitative relevance of our mechanism by calibrating a two-sector version of the model: sector 1 will be the low-tech sector and sector 2 the hightech one. ${ }^{19}$ Since the only available data on public spending composition concern investment, in the calibration exercise we need to reinterpret the model in terms of intermediate goods. As is common in the literature, an alternative interpretation of quality-ladder models is one where households consume a homogeneous consumption good which is assembled from differentiated intermediate goods. The static utility function in (1) can then be interpreted as a CRS production function in which superior quality intermediate goods are more productive in manufacturing the final good. ${ }^{20}$

The exercise consists of choosing the 8 parameters of the model $\left\{D, T_{r}, \rho, \gamma, n, \mu, \lambda_{1}, \lambda_{2}\right\}$ to match salient long-run features of the US economy. Since we work with intermediate goods, we need to choose our unit of time to be large enough to match their average life time. For this purpose we choose five years as our unit of time. ${ }^{21}$ After calibrating the model we explore the effects of government policy on the skill premium between two 5-years periods, 1976-80 and 1987-91. ${ }^{22}$ We compute the increase in the skill premium produced by shocking the model with the change in the composition of public spending showed in figure 1, and compare it with the actual increase observed in the data.

The calibration of some parameters is standard. Since in steady-state $\rho$ is equal to the interest rate $r$, we calibrated it to match a 7 percent average real return on the stock market estimated in Mehra and Prescott (2003); in our five-year time unit this leads to setting $\rho=0.35 .{ }^{23}$ We also explore the sensitivity of the results to calibrating the interest rate to a lower bound of 3 percent, close to the return on riskless assets which is often used in calibrating business cycle models, leading to $\rho=0.15$, and to an upper bound of 10 percent, which is close to Mehra and Prescott estimates of return on assets for some recent subperiods; this leads to $\rho=0.5$.

We calibrate $n$ to match a population growth rate of $1.14 \%$ (Bureau of labor Statistics,1999). Since our time unit is 5 years, both $\rho$ and $n$ must be multiplied by five, as we do in table II below. We choose the total working life time $D=40$ as in Dinopoulos and Segerstrom (1999) and the total schooling time $T_{r}=5$ to match the average years of college in the US - both values must be adjusted

\footnotetext{
${ }^{19}$ All the results obtained for the model with a continuum of sectors hold for this simplified version.

${ }^{20}$ See Grossman and Helpman (1991) ch. 4.

${ }^{21}$ Since there is no capital in the model we consider intermediate goods as fully depreciating every period. Average full depreciation period of intermediate goods is 8-10 years. We choose the lenght of a period to be not greater than the average training time, which we reasonably assume to be 5 years.

${ }^{22}$ We choose 1976-80 as the starting year because it corresponds to the moment when the composition of public spending starts moving faster towards high-tech goods, and it is also very close to the turning point of the dynamics of the skill premium. We limit the analysis to the period 1976-91 because these are the years where the bulk of the increase in the U.S. skill premium took place (see figure 1).

${ }^{23}$ Jones and Williams (2000) suggest that the interest rate in R\&D-driven growth models is also the equilibrium rate of return to R\&D, and so it cannot be simply calibrated to the risk-free rate on treasury bills - which is around $1 \%$. They in fact calibrate their R\&D-driven growth model with interest rates ranging from 0.04 to 0.14 . A different argument suggests that in the presence of efficient financial market the return on R\&D firms stocks will be equalized at the margin to that of risk-free assets, which is around $2-3$ perecent.
} 
for our time unit in table II. ${ }^{24}$ Autor, Katz, and Kruger (1998) show that the relative supply of skills (college and above over non-college) rises from 0.138 in 1970 to 0.25 in 1990 . We follow this evidence by choosing the threshold $\gamma$ to bound the relative supply of skilled workers below 25 percent of the workforce.

The crucial parameters of the calibration are the $R \& D$ difficulty index $\mu$, and the quality jumps of the low and high-tech sectors, $\lambda_{1}$ and $\lambda_{2}$ respectively. We calibrate the quality jumps using estimates of the sectorial markups for 2-digit US manufacturing industries. We use the revised OECD classification of high-tech and low-tech sectors as in Hatzichronoglu (1997). Martins, Scarpetta, and Pilat (1996) provide the most conservative estimates for markups in US manufacturing industries for the period 1970-92, and they also break down the industries according to their R\&D intensity ${ }^{25}$. For the R\&Dintensive industries (our high-tech group) the estimated average markup is 33 percent, while for the medium and low-tech industries the average markup is 13 percent. ${ }^{26}$ In our 5-year time frame this implies setting $\lambda_{1}=(1+0.13 * 5)=1.65$ and $\lambda_{2}=1+0.33 * 5=2.65$. We also explore the sensitivity of our results to setting the difference between the two markups to the maximum obtained by Martins et al. (1996), that is 5 percent low-tech and 54 percent high-tech $\left(\lambda_{1}=1.25\right.$ and $\left.\lambda_{2}=3.7\right)$, and the minimum positive distance, 22 percent for low-tech and 29 percent for high-tech $\left(\lambda_{1}=2.1\right.$ and $\left.\lambda_{2}=2.45\right)$.

Once we have calibrated the two quality jumps we can use the equation for the growth rate to obtain the difficulty index parameter $\mu$ :

$$
g=\frac{\dot{u}}{u}=I \int_{0}^{1} \log \lambda(\omega) d \omega=\frac{n}{\mu} \frac{1}{2}(\ln \lambda(1)+\ln \lambda(2)) .
$$

From the Penn World tables we take an average GDP growth rate for the period 1976-1991 in the US of 2.3 percent and using the quality jumps, calibrated as explained above, we obtain $\mu$ equals to $0.47^{27}$.

To account for the weight of public investment expenditure in the economy we consider government investment as a share of total private investment. ${ }^{28}$ Therefore we set $\beta(\omega)=\frac{G(\omega)}{c}$ and the demand in (8) becomes

$$
\frac{c N(t)}{\lambda(\omega)}+\frac{N(t) \beta(\omega) c}{\lambda(\omega)}=\frac{N(t) c}{\lambda(\omega)}(1+\beta(\omega))=q(\omega)
$$

\footnotetext{
${ }^{24}$ Dinopoulos and Segerstrom (1999) use a training time of four years, we stretch it to five to match our time unit of five years.

${ }^{25}$ These estimates are more conservative than those in previous estimates such as Hall(1990) and Roeger (1995) in that they provide substantially lower values. Lower values are more plausible because they reflect more closely the observed profit rates.

${ }^{26}$ The four high-tech industries are drugs and medicines, office and computing machineries, electrical machineries, and. This is in line with the OECD classification. We are aware of using different sector classifications for markups and for public investment. This is due to lack of estimates of markups for the aggregates equipment and software and strucutures, and to lack of data on goverment spending by industry.

${ }^{27}$ We use equal weights for the two sectors for simplicity. We have also performed the exercise using some measure of the weights of the high-tech and low-tech sectors in the real economy and we get similar results. Using sectoral output shares, for instance, we obtain a 51 percent high-tech share and a 49 percent low-tech share.

${ }^{28}$ Private spending in the model, labeled $c$, is consumption. In the calibration, since we work with investment data, private spending is private investment. Notice that since we do not have data on the structure of public consumption we cannot use GDP as the measure of the size of this economy.
} 
Working out the equilibrium with this modification, reducing the system to one equation - as we did in (A.1.1) - and substituting $w_{H}=\frac{\sigma}{\theta_{0}-\gamma}$ into it we obtain a relation between the skill premium and the composition of public spending (share of low-tech goods $\frac{G(1)}{c}$ and share of high-tech goods $\frac{G(2)}{c}$ ):

$$
\left(\frac{\sigma}{w_{H}}+1-\gamma\right)\left(1-\frac{\sigma}{w_{H}}-\gamma\right) \phi / 2=\frac{n\left(\frac{\sigma}{w_{H}}\right)}{\mu \sigma(\rho+n / \mu-n)}\left(\frac{\frac{\sigma}{w_{H}}+\gamma}{\Gamma+\Psi}\right)(1-\Gamma+\bar{\beta}-\Psi),
$$

where $\bar{\beta}=\int_{0}^{1} \beta(\omega) d_{\omega}$, which in our two-industry version implies $\bar{\beta}=\frac{1}{2}\left(\frac{G(1)}{c}+\frac{G(2)}{c}\right)$, and $\Psi=$ $\int_{0}^{1} \frac{\beta(\omega)}{\lambda(\omega)} d_{\omega}$ becomes $\Psi=\frac{1}{2}\left(\frac{G(1)}{\lambda_{1} c}+\frac{G(2)}{\lambda_{2} c}\right)$. Table I below summarizes our calibration.

TABLE I

SumMARY OF CALIBRATION

\begin{tabular}{cccc}
\hline \hline parameter & value & moment to match & source \\
\hline \hline$D$ & 8 & life time after college & standard \\
$\rho$ & 1 & years of college & standard \\
$n$ & 0.35 & interest rate & Mehra and Prescott $(2003)$ \\
$\gamma$ & 0.07 & population growth rate & Bureau of labor Statistics (1999) \\
$\mu$ & 0.75 & lower-bound for the share of unskilled & Autor, Katz, Kruger (1998) \\
$\lambda_{1}$ & 0.47 & GDP growth rate of 2.3\% & Penn World Tables \\
$\lambda_{2}$ & 1.65 & low-tech markup of 13\% & Martins, Scarpetta, and Pilat (1996) \\
\hline
\end{tabular}

In our quantitative analysis we focus on two relevant 5-year periods: 1976-80, the period right before both the skill premium and the technological bias of public spending start increasing rapidly, and 1987-91, when the bulk of the shock has been consumed. To asses the effect of public spending on wages we use BEA NIPA data on government investment in structure $\left(G_{1}\right)$, our low-tech aggregate, and E\&S $\left(G_{2}\right)$, our high-tech aggregate. ${ }^{29}$ NIPA data on public expenditure shows the following composition in the periods of interest: in 1976-80 average government investment in structure was 29 percent and in E\&S was 7 percent of total private investment $\left(\frac{G_{1}}{c}=0.29\right.$ and $\left.\frac{G_{2}}{c}=0.07\right)$; respectively, in 1987-91 the low-tech expenditure share decreased to 26 percent and the high-tech share rose to 18 percent.

Table II presents the simulation results, the first entry in each columns shows the effect of the public policy shock on the skill premium predicted by the model $\left(\Delta w_{H}^{m} / w_{H}^{m}\right)$, the second entry shows how much of the change in the skill premium observed in the data is explained by our model $\left(\left(\Delta w_{H}^{m} / w_{H}^{m}\right) /\left(\Delta w_{H}^{d} / w_{H}^{d}\right)\right)$. For the observed skill premium we use CPS data from Krusell et al. (2000) on average wages of college graduates and high-school graduates - this is also shown in figure 1. Between the two periods considered this measure of the skill premium increased by 15.8 percent. In the benchmark calibration the policy shock produces a 1.8 percent increase in the skill premium, which accounts for 12 percent of the observed increase in wage inequality.

\footnotetext{
${ }^{29}$ Notice that here we do not exactly use the fiscal policy rules specified in section 5 . This is because in this simplified version of the model those rules would not allow us to catch the entire effect of a change in the composition of public spending on the skill premium. In fact, in the case of extreme asymmetric spending $(\alpha=1)$ our rule predicts that the low-tech sector gets a share of the public spending that is proportional to it's quality jump. While, in the data the extreme asymmetry would mean that the spending going to the low-tech sector would be zero $\left(G_{1}=0\right)$. Thus, to keep the model closer to the data in the quantitative excercise we use directly government investment in the two sectors, as a share of total private investment, as an index of spending composition.
} 
TABLE II

SIMULATION RESULTS

\begin{tabular}{|c|c|c|c|c|c|c|c|c|}
\hline & \multicolumn{6}{|c|}{$\bar{~} \overline{\lambda_{1}, \lambda_{2}}$} \\
\hline & & & $\Delta w_{H}^{m} / w_{H}^{m}$ & $\frac{\Delta w_{H}^{m} / w_{H}^{m}}{\Delta w_{H}^{d} / w_{H}^{d}}$ & $\Delta w_{H}^{m} / w_{H}^{m}$ & $\frac{\Delta w_{H}^{m} / w_{H}^{m}}{\Delta w_{H}^{d} / w_{H}^{d}}$ & $\Delta w_{H}^{m} / w_{H}^{m}$ & $\frac{\Delta w_{H}^{m} / w_{H}^{m}}{\Delta w_{H}^{d} / w_{H}^{d}}$ \\
\hline & bmk & $\rho=0.35$ & 0.018 & 0.12 & 0.0056 & 0.036 & 0.037 & 0.24 \\
\hline$\rho$ & $\min$ & $\rho=0.15$ & 0.023 & 0.15 & 0.0072 & 0.046 & 0.052 & 0.33 \\
\hline & $\max$ & $\rho=0.5$ & 0.014 & 0.09 & 0.0046 & 0.029 & 0.028 & 0.18 \\
\hline
\end{tabular}

The robustness analysis shows that this result is sensitive to the 'technology gap' between the two groups of industries, that is the distance between the quality jump in low and high-tech sectors, $\lambda_{1}$ and $\lambda_{2}$. At the minimum distance, obtained at a low-tech markup of 22 percent and a high-tech markup of 30 percent $\left(\lambda_{1}, \lambda_{2}=2.1,2.45\right)$, the model predicts a very small increase in inequality, consequently a negligible share of inequality is explained by our mechanism (only 3.6 percent). On the other hand, under the maximum technology gap, that is a 5 percent low-tech markup and a 110 percent high-tech markup $\left(\lambda_{1}, \lambda_{2}=1.25,3.7\right)$, the policy shock explains 24 percent of the observed increase in inequality. A second robustness check shows that the results are not too sensitive to changes in the intertemporal preference parameter $\rho$. Calibrating $\rho$ to match a 3 percent interest rate, thus reducing the discount rate to $\rho=0.15$, produces a small increase in the quantitative relevance of the policy mechanism under the benchmark technology gap: the share of inequality attributable to the shock rises from 12 percent to 15 percent. The effect is stronger under the high technology gap, the share of inequality attributable to the policy shock rises from 24 to 33 percent. The opposite result is obtained calibrating $\rho$ to match a 10 percent interest rate.

While the benchmark technology gap should be considered as the most plausible value (we have no arguments for preferring the other values explored above), the upper bound for $\rho$, corresponding to a 10 percent interest rate, can be considered implausible. In fact, most of the growth and business cycle literature calibrates the discount factor to match interest rates in the range $(0.3,0.7)$. It follows that our model can plausibly generate between 12 and 15 percent of the observed change in the skill premium. ${ }^{30}$

Quantitatively our mechanism explains a relatively small but not negligible part of the observed increase in the skill premium. We do not consider this a shortcoming of the paper for the following

\footnotetext{
${ }^{30}$ It is worth noticing that the measure of inequality that we use, $w_{H} / w_{L}$, could overstate the increase in the skill premium when we bring the model to the data. This happens because the average wage of skilled workers in the model is $\int_{\theta_{0}}^{1}(\theta-\gamma) w_{H} d F(\theta)=\left(\theta_{0}+1-2 \gamma\right) w_{H}$, the skilled wage times the average quality (efficiency) of skilled workers, which is smaller than $w_{H}$. We do not use this measure in the calibration because there is a semplification in the model that counterbalances the overstatement of the skill premium generated by using $w_{H}$ as average skilled wages. In fact we assumed that unskilled workers do not accumulate human capital, and so their average wage is simply $w_{L}$. In the data average wages of both skilled and unskilled are computed taking into account the 'abilities', or human capital, of heterogeneous workers in the two groups. Hence, using $w_{L}$ in the model for the average unskilled wage understates the real measure of the skill premium. Our take is to leave human capital accumulation out of the measure of inequality in the calibration to avoid distortions in both directions. Nevertheless, we have run our simulation for the average skill premium in the model, and as expected the quantitative effects of the policy shock is smaller but not substantially: with the benchmark calibration the model explains 9 instead of 12 percent of the observed increase in inequality. The reduction in the quatitative effects is due to the fact that when the relatice supply of skills increases the average quality of skilled workers declines, while by construction the model cannot account for the reduction in the average quality of unskilled workers, since the unskilled wage is fixed to 1.
} 
reasons: first, as well recognized in the literature, the increase in the US skill premium in the period between the late 1970s and the 1990s cannot be attributable to a single factor. Technical change, institutional change (i.e. minimum wages and deunionization), and globalization (i.e., North-South and North-North trade, offshoring, and technology diffusion) all seem to have contributed to some extent to the observed changes in the wage structure (see i.e. Di Nardo, Fortin, and Lemieux, 1996, Autor and Katz, 1999, Card and Di Nardo, 2002, Feenstra and Hanson, 2003). Secondly, in the literature focusing on the endogenous bias of technical change, to which our paper belongs, we either do not find any attempt at a quantitative evaluation of the mechanism studied theoretically, or we find quantitative evaluations supporting the view that no single source of technical change can be viewed as "the" main factor behind wage inequality. The quantitative relevance of Acemoglu's directed technical change model has not being assessed yet ${ }^{31}$. The calibration in Dinopoulos and Segerstrom (1999) shows that a decrease in the common tariff between the US and its (Northern) trade partners from 27 percent in the 1970 to 2.5 in 1990 increases the skill premium by 4.5 percent, which account for about 25 percent of the total increase in the skill premium. A value higher then the one we find but surely not explaining most the observed increase in inequality.

Finally, the broad goal of this paper is that of proposing a first attempt at a quantitative evaluation of the role of innovation policy in shaping technical change and the wage structure. Government investment composition is only one part of the shift in the structure of innovation policy that took place in the 1970s and 1980s, and we do not expect it to have a very large effect on the wage premium. We do expect, though, that with the availability of better data (i.e. data that include the technological composition of public consumption and more disaggregated sectorial and firm-level data) the composition of public spending together with the supply-side policies discussed in the section 2 may explain a larger share of the increase in the US wage inequality.

\section{Transitional dynamics}

The model presented in this paper allows us to capture the effects of a change in the composition of public spending on the skill premium. We have shown in the previous steady-state analysis that permanent changes in the composition of public spending in favour of innovative goods can explain permanent changes in the skill premium in the US between 1976 and 1991. This approximates what happened in the economy, where of course changes in all variables have taken place more gradually. For example, the change in government expenditure composition shown in the stylized facts section was gradual and relatively steady. Since we are assuming rational expectations, it is desirable to assume that the decision makers in the stylized economy we are analyzing learned at some point that such a policy break was taking place. In fact, a sequence of surprises would hardly be consistent with the quite regular pattern of public spending change observed in the data.

Hence, we deem it important to test our model's prediction in the face of the assumption that

\footnotetext{
${ }^{31}$ One reason for this is that for the source at the roots of the endogenous bias of technical change they focus on, the increase in the relative supply of skills, to produce any positive effect on the skill premium, the elasticity of substitution between skilled and unskilled workers must be above 2, while all major estiamates point to a value around or below 1.5 (see Acemoglu, 2002a).
} 
agents knew at the beginning of the period, 1976, the paradigm shift that would gradually have brought the government expenditure composition up to its 1991 level. This assumption is most natural within the fully rational expectations approach we are adopting. Specifically, let us - as before - call $\beta_{t}(\omega)$ the time $t$ value of government expenditure in sector $\omega \in[0,1]$ as a fraction of private consumption. Let us assume that these fractions change according to the following differential equations:

$$
\dot{\beta}_{t}(\omega)=(1-\psi)\left(G(\omega)-\beta_{t}(\omega)\right), \omega \in[0,1]
$$

where $G(\omega), \omega \in[0,1]$ are the long-run (steady-state) government expenditure shares and $\psi<1$. Equations (24) are globally stable, and the lower $\psi$ the quicker the government expenditure speed of adjustment toward the new steady state. The paradigm shift occurred after 1976 can be interpreted as a sudden permanent change in $G(\omega)$ : the new values of the $G(\omega), \omega \in[0,1]$ implies that the old steady state is left forever and the economy sluggishly starts heading to the new one, according to eq.s (24). Under rational expectations all the relevant effects of the new eq.s (24) are assumed to be correctly anticipated by the agents. Of course, such transitional dynamics behavior of the policy variables entails a transitional dynamics behavior of all the endogenous variables. More importantly, the expectation of a transition in the government expenditure composition during the relevant period affects the individual education and consumption decisions, wages, as well as firm production and R\&D employment decisions.

When incorporating a permanent change in vector $G(\omega), \omega \in[0,1]$ of eq.s (24) in a fully dynamic version of our model, there is a number of technical issues to consider, as the forward-looking aspect of the educational choice renders time $t$ 's schooling choice dependent on the whole future trajectory of the skill premium and of the interest rates, which are necessarily off their steady state values. ${ }^{32}$ Moreover, the values of the stock variables - human capital and technological difficulty indexes - after the shift would still reflect for long time the results of the past education and R\&D employment choices. This renders the formal derivation of the dynamics very challenging, because in some of the differential equations state variables values are forwarded or lagged in time. However, a discretized version of these equations can be solved and their stability properties analyzed. We solve the transitional dynamics numerically, and report the results in figure 3 below. All our simulations satisfy Blanchard-Kahn conditions and hence the equilibrium trajectories obtained are unique. Moreover, we do not restrict the analysis to a local approximation, but simulate the whole non-linear saddle paths. Consistently with our previous steady-state analysis, we have coarsely partitioned the set of industries into "low tech" industries and "high tech" industries, assuming an equal weight ${ }^{33}$. All parameters have been calibrated from their steady-state values, as shown in the previous section. In what follows, we show the numerical simulations of the whole transitional paths of the relevant endogenous variable in response to the change in the government expenditure expected (future) steady-state levels. The only simplifying assumption that we adopt in the simulation of the transition paths is that of keeping the interest rate at its steady-state value, calibrated at 7 percent. This is motivated by the fact that in the data the average return on assets do not vary much in the period considered (see Mehra and

\footnotetext{
${ }^{32}$ The equilibrium dynamic systems of equations is derived in appendix II.

${ }^{33}$ This could be easily generalized.
} 
Prescott, 2005). The results are reported in figure 3 below.

\section{[Figure 3 about here]}

As in the comparative statics exercise of the previous section, we let the public spending composition change from its $1976-80$ value, $G_{1} / c=0.29$ and $G_{2} / c=0.07$, to its $1987-91$ value $G_{1} / c=0.26$ and $G_{2} / c=0.18$. This time though, the change from the initial to the final period will take place gradually according to (24). In the figure, we can see how the trajectories of government spending, which represent our policy shock, evolve, and the effect they produce on the endogenous variables of the model. ${ }^{34}$ All responses of endogenous variables to the policy shock are in line with what we found in the steady-state analysis in proposition 2, and in its quantitative application in the previous section. More precisely, the high-tech arrival rate of innovation increases and then, as the high-tech $\mathrm{R} \& \mathrm{D}$ difficulty increases, slowly returns to the exogenous steady-state level $n / \mu$. The education choice mechanism implies that in equilibrium the employment of skilled workers increases as well. The lowtech sector shows a similar dynamics but in the opposite direction. These shifts in employment imply that the relative employment of unskilled workers, $\theta_{0}(t)$, decreases. Contemporary to skill upgrading, as the composition of public spending rises, the relative wage of skilled workers increases, thus qualitatively reproducing the dynamics of the skill premium observed in the data. The speed of convergence looks very slow because we have approximated continuous time with a large number of discrete subperiods. Of course the aim of this transitional dynamics exercise is merely to show that qualitatively realistic trajectories can be generated by our fully rational general equilibrium model.

\section{Conclusions}

In this paper we have shown that the technological content of government spending played a significant role in explaining the wave of innovations that hit the US economy in recent decades and its effects on the wage structure. The interaction between policy and the heterogeneous industry structure yields the basic theoretical contribution of the paper: a shift in the composition of public spending towards highly innovative sectors increases aggregate expenditure in innovation and the skill premium.

We identify and quantify the role of a new source of technical change, the technological composition of public spending, which complements the role of international trade (Dinopoulos and Segerstrom 1999 and Acemoglu 2003) and of the relative supply of skills (Acemoglu 1998 and 2002b, and Kiley 1998 ) in endogenizing the factor bias of technical change. ${ }^{35}$ In a calibrated version of the model we show that the shift of US public spending toward more innovative industries can explain between 12 and 15 percent of the observed increase in the skill premium between 1976 and 1991.

This paper represents a first attempt to evaluate the effects of fiscal policy on technology and wages and is amenable to many extensions. First, further research could be devoted to fill the data gap that

\footnotetext{
${ }^{34}$ Here we have set our unit of time to 1 because simulating the model for many periods improves the convergence properties of the solution algorithm.

${ }^{35}$ It is worth stressing once again that our model is not, strictly speaking, a model of skill-biased technical change. However, introducing endogenous factor-bias in the set-up and assuming that high-tech goods are produced by skilled workers and low-tech goods by unskilled workers, the composition of government spending would have the same qualitative effects on inequality.
} 
prevents a more complete evaluation of the magnitude of the policy effects on wages. Lacking data on the technological composition of aggregate government procurement, in our empirical analyses we have used the only available sub-sample: the composition of government investment. Despite the support for our theory provided by such data, a larger sample of government procurement would certainly refine the results. Hence, some effort could be devoted to the collection of data on the composition of public consumption between high-tech and low-tech sectors; this would allow for a better quantitative assessment of our demand-side policy channel.

A second line of future research would involve a more complete investigation of the policy channel by explicitly modeling the supply-side innovation policy tools introduced in the 1980s and discussed in section 2, together with the demand-side policy explored in this paper, and evaluate the overall effect of these policies on the factor bias of technical change and on wage inequality. Impullitti (2008b) shows that a major obstacle in this direction of research is the difficulty of quantifying the economic magnitude of the supply-side policies.

The theoretical link between the composition of government spending and long-run growth is of some interest in itself - besides the implications for wage inequality explored here - and worth of further research. The paper highlights a mechanism of revenue-neutral selective growth policy that can be relevant for recent policy debates, especially in those countries that, burdened by large public debt, wish to stimulate growth without using deficit spending. For instance, low-cost growth policies have recently played a central role in the debate on the implementation of the Lisbon Agenda in the E.U.. (see Sapir 2003). The existing papers tackling the effect of the composition of public spending on growth focus on different dimensions of spending composition, such as public goods versus transfers, but cannot focus on the sectorial composition because they use models with homogeneous industries (i.e. Peretto, 2003, and 2007). In the companion paper, Cozzi and Impullitti (2008), we complement the existing literature using our model to analyze the interaction between the composition of fiscal policy (taxes and spending) and the asymmetric-industry structure, exploring the implications for growth. In both the semi-endogenous and the fully-endogenous growth framework we analyze how fiscal policy can be used to select the most dynamic industries and promote growth.

\section{Appendix I: proofs}

Proof of the existence of the steady state. Solving (18) for $x(\omega)$ and integrating it w.r.t. $\omega$ we get:

$$
\bar{x}=\frac{\theta_{0}-\gamma}{b \sigma(\rho+n / \mu-n)}\left[\left(\theta_{0}-\Omega\right)\left(\Gamma^{-1}-1\right)+(\bar{G}-\Omega)\right]
$$

and substituting this into (19) we obtain the following synthetic equilibrium condition:

$$
\left(\theta_{0}+1-2 \gamma\right)\left(1-\theta_{0}\right) \phi / 2=\frac{n\left(\theta_{0}-\gamma\right)}{\mu \sigma(\rho+n / \mu-n)}\left[\left(\theta_{0}-\Omega\right)\left(\Gamma^{-1}-1\right)+(\bar{G}-\Omega)\right] .
$$

The LHS of this eq. (A11) is a strictly concave quadratic polynomial with roots on $2 \gamma-1$ and 1 , and the RHS of eq. (A11) is a strictly convex quadratic polynomial with roots $\gamma$ and $\frac{\Omega-\Gamma \bar{G}}{1-\Gamma}$. It follows 
that, if the stated parameter restrictions are satisfied, there exists always one and only one real and positive solution $\theta_{0} \in(\gamma, 1)$. The proof follows from the fact that the specified parameter restriction allows the intercept (the value of the polynomial at $\theta_{0}=0$ ) of the LHS polynomial to be bigger than in intercept of the RHS polynomial. Specifically $L H S(0)>R H S(0)$ implies:

$$
(1-2 \gamma) \phi / 2>\frac{n \gamma}{\mu \sigma(\rho+n / \mu-n)}\left(\frac{\Omega-\Gamma \bar{G}}{\Gamma}\right),
$$

which rearranged leads to the parameter restriction. It is easy to see that this condition allows for a unique solution $^{36}$. Moreover for Minkowski's inequality $\Omega-\Gamma \bar{G}<0$, therefore when $1-2 \gamma>0$ no restriction on parameters is needed for a unique solution.

Proof of Proposition 1.a. Solving (18) for $x(\omega)$ we get:

$$
\left(\frac{\lambda(\omega)-1}{\lambda(\omega)}\right)\left(\frac{\theta_{0}-\Omega}{\Gamma}+G_{\omega}\right) \frac{\theta_{0}-\gamma}{b \sigma(\rho+n / \mu-n)}=x(\omega),
$$

and deriving w.r.t. $G_{\omega}$ we obtain

$$
\frac{\partial x(\omega)}{\partial G_{\omega}}=\left(\frac{\lambda(\omega)-1}{\lambda(\omega)}\right) \frac{\theta_{0}-\gamma}{b \sigma(\rho+n / \mu-n)},
$$

which is always positive since $\lambda(\omega)>1, \theta_{0}>\gamma$ and $\rho>n$. From this derivative we can also see that $\partial x(\omega) / \partial G_{\omega}>\partial x(\omega) / \partial G_{\omega^{\prime}}$ when $(\lambda(\omega)-1) / \lambda(\omega)>(\lambda(\omega)-1) / \lambda(\omega)$ which is always true if $\lambda(\omega)>\lambda(\omega)$.

Proof of Proposition 1.b Rearranging (A11) we get a single polynomial in $\theta_{0}$ and $\Omega$ :

$$
F\left(\theta_{0} ; \Omega\right)=\frac{n\left(\theta_{0}-\gamma\right)}{\mu \sigma(\rho+n / \mu-n)}\left[\left(\theta_{0}-\Omega\right)\left(\Gamma^{-1}-1\right)+(\bar{G}-\Omega)\right]-\left(\theta_{0}+1-2 \gamma\right)\left(1-\theta_{0}\right) \phi / 2 .
$$

Using the Implicit Function Theorem we get:

$$
\begin{gathered}
\frac{d \theta_{0}}{d \Omega}=\frac{-\partial F / \partial \Omega}{\partial F / \partial \theta_{0}}= \\
=\frac{\frac{n\left(\theta_{0}-\gamma\right)}{\mu \sigma(\rho+n / \mu-n) \Gamma}}{\frac{n}{\mu \sigma(\rho+n / \mu-n)}\left[\left(\theta_{0}-\Omega\right)\left(\Gamma^{-1}-1\right)+(\bar{G}-\Omega)\right]+\frac{n\left(\theta_{0}-\gamma\right)}{\mu \sigma(\rho+n / \mu-n)}\left(\Gamma^{-1}-1\right)+\phi\left(\theta_{0}-\gamma\right)}>0
\end{gathered}
$$

This results follows from the fact that $\theta_{0}>\gamma, \rho>n, \Gamma^{-1}>1$ and finally, from (A1) we know that the expression inside the square brackets is greater than zero.

\section{Appendix II: transitional dynamics}

The schooling choice leading to eq. (4) in the paper implies, off steady states, the following ability threshold $\theta_{0}(t)$ :

\footnotetext{
${ }^{36}$ It is easy to check that all parameters restriction are satisfied by the number we use in the calibration excercise.
} 


$$
\theta_{0}(t)=\gamma+\frac{\int_{t}^{t+D} e^{-\int_{t}^{s} r(\tau) d \tau} d s}{\int_{t+T r}^{t+D} e^{-\int_{t}^{s} r(\tau) d \tau} w_{H}(s) d s} .
$$

In our numerical simulations we have chosen to set $r(t)=\rho$, which facilitates the convergence of the numerical algorithm. In fact, though the analysis could be generalized, since in our relatively long time period the exogenous policy variables $G$ modify substantially from initial to the final steady state, convergence is much for difficult to achieve than in a more standard local analysis. Hence the previous equation becomes:

$$
\theta_{0}(t)=\gamma+\frac{\frac{1-e^{-D \rho}}{\rho}}{\int_{t+T r}^{t+D} e^{-\rho(s-t)} w_{H}(s) d s} .
$$

Defining: $W_{S}(t)=\int_{t+T r}^{t+D} e^{-\rho(s-t)} w_{H}(s) d s$ and differentiating with respect to $t$ :

$$
\dot{W}_{S}(t)=e^{-\rho D} w_{H}(t+D)-e^{-\rho T r} w_{H}(t+T r)+\rho W_{S}(t),
$$

which in the steady state implies: $W_{S}=\frac{e^{-T r \rho}-e^{-D \rho}}{\rho} w_{H}$. In light of the previous definitions, we can rewrite eq. (25) as:

$$
\theta_{0}(t)=\gamma+\frac{1-e^{-D \rho}}{\rho W_{S}(t)}
$$

In the steady state: $\theta_{0}=\gamma+\frac{1-e^{-D \rho}}{\left(e^{-T r \rho}-e^{-D \rho}\right) w_{H}}$.

Let us remind that population growth rate $n$, birth rate $\beta$ are linked by: $\beta=\frac{n e^{n D}}{e^{n D}-1}$. Unskilled labor supply is:

$$
M(t)=\beta N(t) \int_{t-D}^{t} e^{n(s-t)} \theta_{0}(s) d s,
$$

where $\beta$ is the birth rate, $N_{t}$ is the population at time $t$, and $\theta_{0}(s)$ is the education ability threshold at time $s$. We stationarize unskilled labour supply by dividing it by the population level, $m(t) \equiv \frac{M(t)}{N(t)}$. Differentiating with respect to time:

$$
\dot{m}(t)=\beta \theta_{0}(t)-\beta e^{-n D} \theta_{0}(t-D)-n m(t)
$$

The unskilled labour market equilibrium (where 1 stands for low tech 2 for high tech - using equal weight for each) is:

$$
m(t)=\frac{1}{2}\left(\left(c(t)+\beta_{1}(t) c(t)\right) / \lambda_{1}\right)+\left(\left(c(t)+\beta_{2}(t) c(t)\right) / \lambda_{2}\right),
$$

where $\beta_{1}(t)$ is the government expenditure in low tech products as a fraction of private consumption and $\beta_{2}(t)$ is the government expenditure in high tech products as a fraction of private consumption. These shares change according to differential equations:

$$
\begin{aligned}
& \dot{\beta}_{1}(t)=(1-\psi)\left(G_{1}-\beta_{1}(t)\right), \text { and } \\
& \dot{\beta}_{2}(t)=(1-\psi)\left(G_{2}-\beta_{2}(t)\right),
\end{aligned}
$$


where $G_{1}$ and $G_{2}$ are the long run (steady state) government expenditure shares, as in (a two sector approximation of) eq. (24).

Aggregate human capital in efficiency units (skilled labor supply) is:

$$
H(t)=\beta N(t) \int_{t-D}^{t-T r} \frac{e^{n(s-t)}\left(1-\theta_{0}(s)\right)\left(1+\theta_{0}(s)-2 \gamma\right)}{2} d s .
$$

Dividing by population, $h(t) \equiv H(t) / N(t)$, and differentiating with respect to time:

$\dot{h}(t)=-n h(t)+\frac{\beta}{2} e^{-n T r}\left(1-\theta_{0}(t-T r)\right)\left(1+\theta_{0}(t-T r)-2 \gamma\right)-\frac{\beta}{2} e^{-n D}\left(1-\theta_{0}(t-D)\right)\left(1+\theta_{0}(t-D)-2 \gamma\right)$,

implying steady state level $h=\beta \frac{\left[e^{n(-T r)}-e^{n(-D)}\right]\left(1-\theta_{0}\right)\left(1+\theta_{0}-2 \gamma\right)}{2 n}$.

We know from the definitions in the text that the arrival rate of innovation in industry $\omega \in[0,1]$ at time $t$ is $I(\omega, t)$ and the per capita technological complexity index follows: $\frac{\dot{x}(t, \omega)}{x(t, \omega)}=\mu I(t, \omega)-n$. In our case we have only two groups of sectors (low technology and high technology), hence we only have:

$$
\begin{aligned}
& \frac{\dot{x}_{1}(t)}{x_{1}(t)}=\mu I_{1}(t)-n \text { and } \\
& \frac{\dot{x}_{2}(t)}{x_{2}(t)}=\mu I_{2}(t)-n .
\end{aligned}
$$

Hence the skilled labour market equilibrium (where 2 for high tech and 1 for low tech - using equal weight for each) is:

$$
h(t)=\frac{1}{2} I_{1}(t) x_{1}(t)+\frac{1}{2} I_{2}(t) x_{2}(t) .
$$

Notice that, from the main text, the free entry condition into R\&D is

$$
v(t, \omega)=b w_{H} x(t, \omega),
$$

and the Euler equation is:

$$
\frac{\dot{c}(t)}{c(t)}=r(t)-\rho
$$

Rewriting the main text eq. (12) as

$$
\begin{aligned}
& v_{1}(t)=\frac{\frac{\lambda_{1}-1}{\lambda_{1}}\left(c(t)+\beta_{1}(t)\right)}{\rho+I_{1}(t)-\frac{\dot{v}_{1}(t)}{v_{1}(t)}-n}, \text { and } \\
& v_{2}(t)=\frac{\frac{\lambda_{2}-1}{\lambda_{2}}\left(c(t)+\beta_{2}(t)\right)}{\rho+I_{2}(t)-\frac{\dot{v}_{2}(t)}{v_{2}(t)}-n}
\end{aligned}
$$

Eq.s (A 2.4)- (A 2.14b) incorporates a system of delayed differential equations in the following unknown functions of time: $\theta_{0}(t), c(t), W_{S}(t), w_{H}(t), h(t), m(t), \beta_{1}(t), \beta_{2}(t), x_{1}(t), x_{2}(t), I_{1}(t)$, $I_{2}(t), v_{1}(t), v_{2}(t)$. They cannot be solved analytically, but we can discretize them and simulate them numerically. This has been done in the text. The existence of leads and lags implies a large number of eigenvalues. Our discrete time simulations have been carried out using Matlab and Dynare softwares ${ }^{37}$.

\footnotetext{
${ }^{37}$ The. $\bmod$ files used for the simulation and the. $\mathrm{m}$ files used to find the steady state are available upon request to the authors.
} 
In our simulations, the steady state was saddle point stable and the Blanchard-Kahn conditions for the determinacy of the equilibrium were satisfied.

\section{References}

[1] Acemoglu D. (2002a). "Technical Change, Inequality and the Labor Market", Journal of Economic Literature, XL, pp. 7-72.

[2] Acemoglu D. (2002b). "Directed Technical Change", Review of Economic Studies.

[3] Acemoglu, D. (2003). "Patterns of Skill Premia", Review of Economic Studies, volume 70, pp. 199-230.

[4] Aghion P., and P. Howitt (1992). "A Model of Growth through Creative Destruction", Econometrica 60(2): 323-351.

[5] Aghion, P., P. Howitt, and G. Violante. (2002). "General Purpose Technology and Wage Inequality," Journal of Economic Growth, vol. 7(4), December 2002, 315-345.

[6] Aghion, P., and P. Howitt, (2006), "Appropriate Growth Policy: A Unifying Framework", Journal of the European Economic Association, 4, p. 269-314.

[7] Aghion, P., and P. Howitt, (2005) "Growth with Quality-Improving Innovations: An Integrated Framework", Handbook of Economic Growth, Volume 1A, Aghion P. and S.N. Durlauf (Eds.), Amsterdam, North-Holland, 2005, 67-110

[8] Autor, D., and L. Katz, (1999) "Changes in the Wage Structure and Earnings Inequality", Handbook of Labor Economics, Vol 3A, Amsterdam, North Holland.

[9] Berman, E., J. Bound, and Z. Griliches, (1994). "Changes in the Demand for Skilled Labor within U.S. Manufacturing Industries: Evidence from the Annual Survey of Manufactures," Quarterly Journal of Economics, Vol. 106, No. 2, pp. 367-397.

[10] Card, D., and J. Di Nardo, (2002) "Skill-Biased Technological Change and Rising Wage Inequality: Some Problems and Puzzles", Journal of Labor Economics, Vol. 20, No. 4 (Oct., 2002), pp. 733783

[11] Caselli, F. (1999). "Technological Revolutions," American Economic Review, 89, 1, 78-102.

[12] Cozzi, G. (2007), "Self-fulfilling prophecies in the quality ladders economy", Journal of Development Economics, vol. 84(1), pp. 445-464.

[13] Cozzi, G. (2008), "Can social norms affect the international allocation of innovation?", Working Papers 2008_2, Department of Economics, University of Glasgow.

[14] Cozzi, G, and G. Impullitti, (2008). "Fiscal policy, Heterogeneous Industries, and Long-run Growth," mimeo. 
[15] Cummins J., and G. Violante (2002). "Investment-Specific Technical Change in the US (19472000): Measurement and Macroeconomic Consequences", Review of Economic Dynamics, vol. 5(2), April 2002, 243-284.

[16] DiNardo, J., N. Fortin, and T. Lemieux (1996). "Labor Market Institutions and the Distribution of Wages, 1973-1992: A Semiparametric Approach", Econometrica, Vol. 64, No. 5 (Sep., 1996), pp. 1001-1044

[17] Dinopoulos E. and P. Segerstrom. (1999). "A Schumpeterian Model of Protection and Relative Wages," American Economic Review 89, 450-472.

[18] Dinopoulos E. and P. Thompson. (1998). "Scale Effects in Schumpeterian Models of Economic Growth", Journal of Evolutionary Economics, 157-85.

[19] Engle R. and B. Yoo (1987). "Forecasting and Testing in Co-Integrated Systems", Journal of Econometrics 35, 143-159.

[20] Feenstra, R., and G., Hanson, (2003) "Global Production Sharing and Rising Inequality: A Survey of Trade and Wages", in Kwan Choi and James Harrigan, eds., Handbook of International Trade, Basil Blackwell.

[21] Galor Oded and Omer Moav, "Ability Biased Technological Transition, Wage Inequality, and Economic Growth," Quarterly Journal of Economics , 115, May, 469-498.

[22] Gort M, Greenwood J., and P. Rupert (1999). "Measuring the Rate of Technological Progress in Structures," Review of Economic Dynamics, 2, 207-30

[23] Grossman G. M. and E. Helpman. (1991). Innovation and Growth in the Global Economy. Cambridge: MIT Press.

[24] Ham, R. M., and D. Mowery. (1999). "The U.S. Policy Response to Globalization: Looking for the Keys Under the Lamp Post", in J. Dunning, ed., Governments and Globalization, Oxford University Press.

[25] Hall, B. (1993). "R\&D Tax Policy During the Eighties: Success or Failure?" Tax Policy and the Economy 7: 1-35.

[26] Hart, D. (1998). "U.S. Technology Policy: New Tools for New Times," NIRA Review, (Summer 1998), pp. 3-6.

[27] Hatzichronoglou, T. (1997). "Revision of the High-Technology Sector and Product Classification", OECD STI Working papers GD (97) 216.

[28] Hornstein, Andreas, Per Krusell, and Gianluca Violante (2005). "The Effects of Technical Change on Labor Market Inequalities," Handbook of Economic Growth, (Philippe Aghion and Steven Durlauf, Editors), North-Holland. 
[29] Howitt, P. (1999). "Steady Endogenous Growth with Population and R\&D Inputs Growing." Journal of Political Economy 107, August: 715-30.

[30] Impullitti, G. (2008a). "International Competition and U.S. R\&D Subsidies: a Quantitative Welfare Analysis," EUI ECO Working paper, 2008/11.

[31] Impullitti, G. (2008b). "Shifting Patterns: U.S. Technology Policy in the 1980s," mimeo EUI Florence and IMT Lucca.

[32] Jones C. (1995). "Time Series Tests of Endogenous Growth Models", Quarterly Journal of Economics $110,495-525$.

[33] Jones C. (2005). "Growth in a World of Ideas", Handbook of Economic Growth, forthcoming.

[34] Jones C. and J. Williams (2000). "Too Much of a Good Thing? The Economics of Investment in R\&D", Journal of Economic Growth, Vol. 5, No. 1, pp. 65-85.

[35] Kiley, M. (1999). "The Supply of the Skilled Labor and Skill-Biased Technological Progress", Economic Journal. 109, pp.708-724.

[36] Krusell, P., L. Ohanian, J.V. Rios-Rull and G. Violante (2000): "Capital-Skill Complementarity and Inequality", Econometrica, 68:5, 1029-1054.

[37] Lictenberg, F.R. (1995). "Economics of Defense R\&D," in Hartley, Keith and Sandler, Todd ed. Handbook of Defense Economics, New York, Elsevier Science B.V.

[38] Machin, S. and J. Van Reenen (1998). "Technology and Changes in Skill Structure: Evidence From Seven OECD Countries", Quarterly Journal of Economics 113, 1215-44.

[39] Mehra,R., and E.C.Prescott.(1985). "The Equity Premium: A Puzzle,” Journal of Monetary Economics 15, 145-161.

[40] Mowery, D. (1998). "The Changing Structure of the U.S. National Innovation System: Implications for International Conflict and Cooperation in R\&D Policy," Research Policy 27, 639-654.

[41] Mowery, D. and N. Rosenberg (1989). Technology and the Pursuit of Economic Growth, Cambridge University Press.

[42] National Science Foundation (2002). Science and Engineering Indicators 2002.

[43] O'Hanlon, M. (2000). Technological Change and the future of Warfare. Brookings Institution Press, Washington, D.C.

[44] Peretto, P. (1998). "Technological Change and Population Growth", Journal of Economic Growth, Vol. 3, No. 4, pp. 283-311.

[45] Peretto, Pietro. (2003)." Fiscal Policy and Long-Run Growth in R\&D-Based Models with Endogenous Market Structure," Journal of Economic Growth, vol. 8(3), pp. 325-47. 
[46] Peretto, P. (2007). "Corporate Taxes, Growth and Welfare in a Schumpeterian Economy", Journal of Economic Theory, Vol. 137, pp. 353-382.

[47] Roeger, W. (1995). "Can Imperfect Competition Explain the Difference between Primal and Dual Productivity Measures? Estimates for US Manufacturing", Journal of Political Economy 103, 2, 316-330.

[48] Ruttan, V. P. (2003). "Military Procurement and Technology Development", University of Minnesota, mimeo.

[49] Sapir, A. (editor) (2004). An Agenda for a Growing Europe: The Sapir Report, Oxford University Press, Oxford.

[50] Segerstrom P. (1998). "Endogenous Growth Without Scale Effects", American Economic Review 88, 1290-1310.

[51] Violante, G. (2002). "Technological Acceleration, Skill Transferability and the Rise of Residual Inequality," Quarterly Journal of Economics, vol. 117(1), February 2002, 297-338. 
Figure 1. Government spending composition and the skill premium: 1963-99

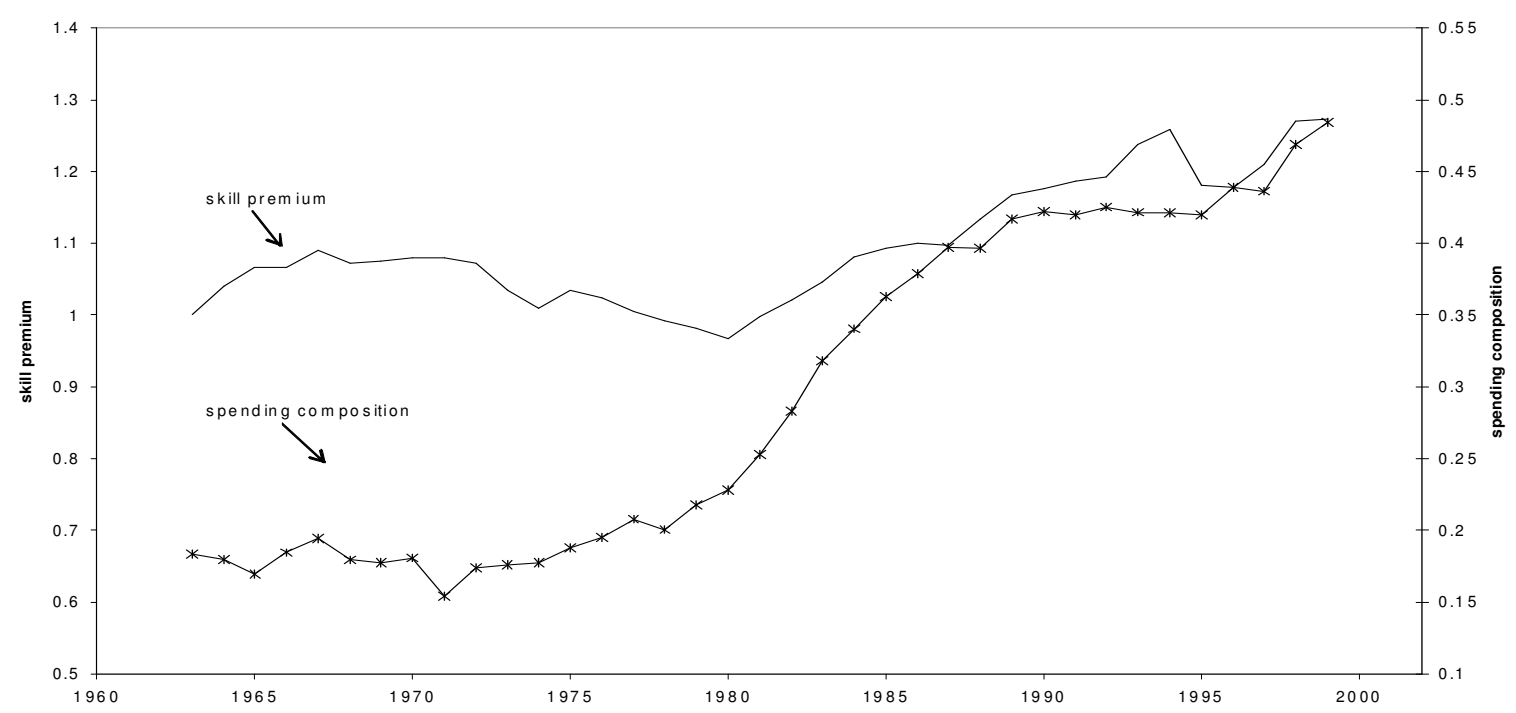

Source: BEA NIPA tables sec. 5 for government spending composition, and the skill premium is taken from Krusell et al. (2000) and CPS (1999). Government spending composition is government investment in R\&S as a share of total public investment.

Figure 2. Private $R \& D$ spending and the skill premium

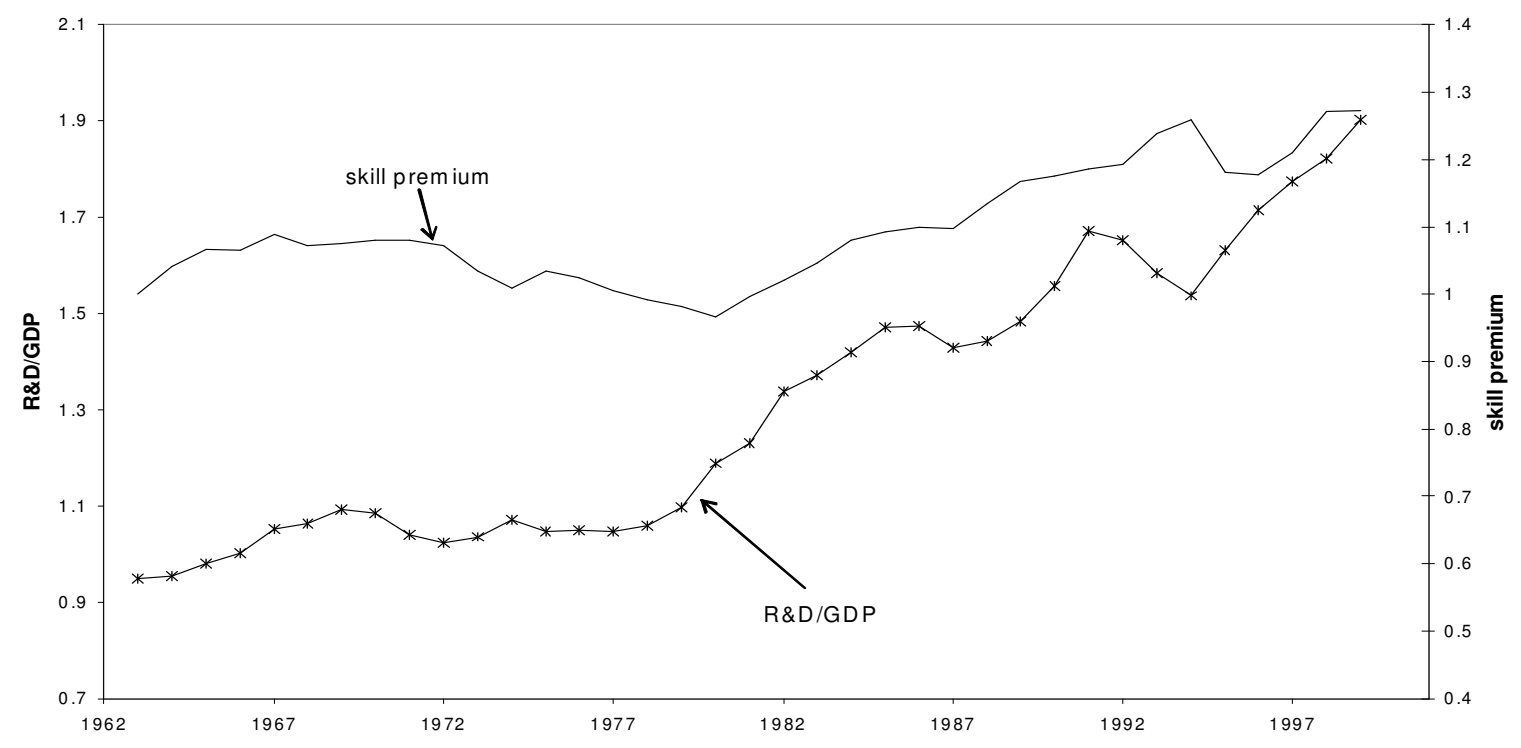

Source: R\&D data are taken from NSF Science and Engineering indicators (2004). 
Figure 3. Transitional dynamics
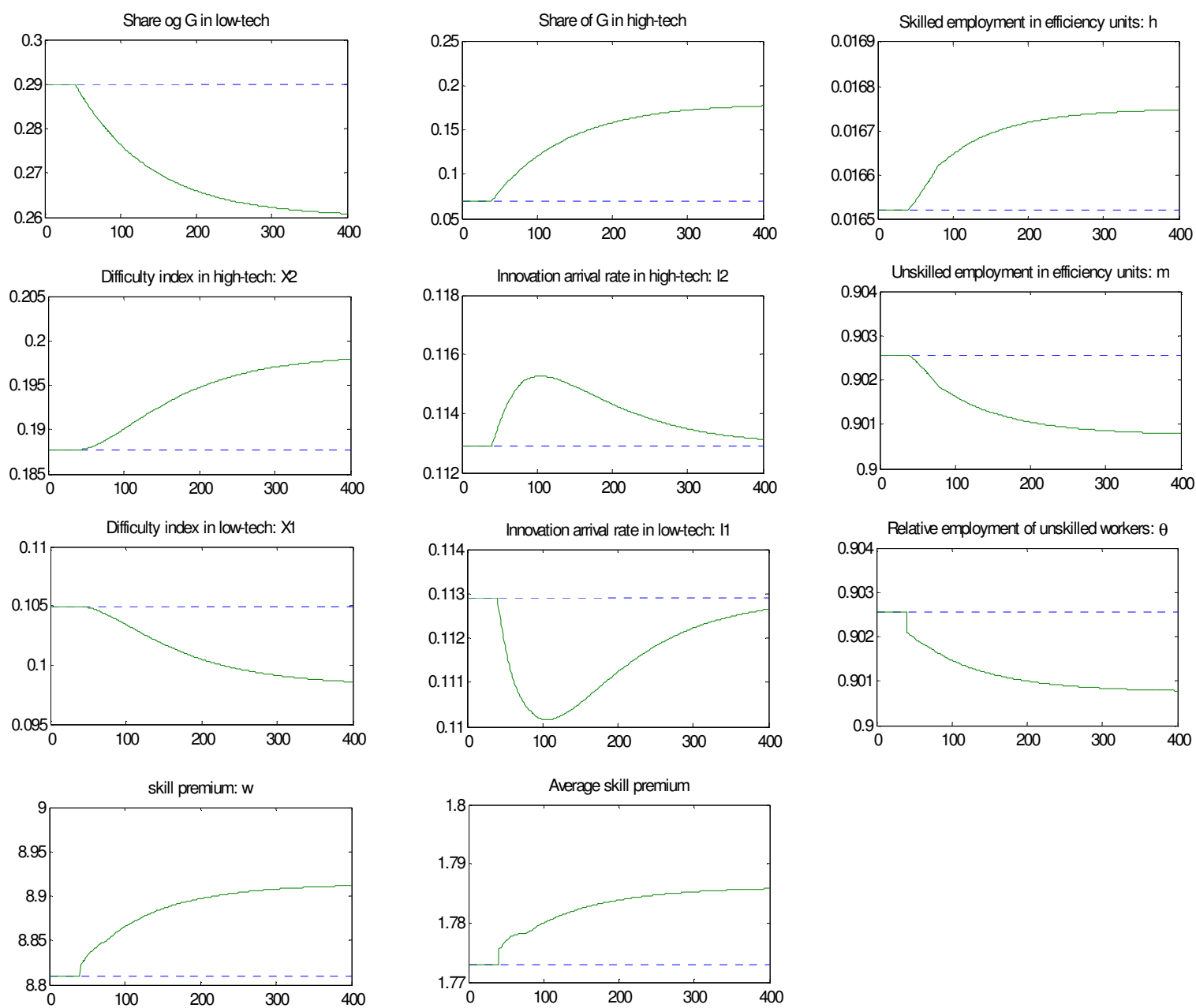

Note: the dotted lines represent the initial position of the economy 